\title{
Transpiration and $\mathrm{CO}_{2}$ fluxes of a pine forest: modelling the undergrowth effect
}

\author{
V. Rivalland ${ }^{1}$, J.-Ch. Calvet ${ }^{1}$, P. Berbigier ${ }^{2}$, Y. Brunet ${ }^{2}$, and A. Granier ${ }^{3}$ \\ ${ }^{1}$ Météo-France/CNRM, 42 Av. Coriolis, F-31057 Toulouse Cedex 1, France \\ ${ }^{2}$ INRA/Bioclimatologie, Domaine de la Grande Ferrade, F-33883 Villenave d'Ornon Cedex, France \\ ${ }^{3}$ INRA/Ecologie et Ecophysiologie Forestière, F-54280 Champenoux, France
}

Received: 12 February 2004 - Revised: 18 November 2004 - Accepted: 22 November 2004 - Published: 28 February 2005

\begin{abstract}
A modelling study is performed in order to quantify the relative effect of allowing for the physiological properties of an undergrowth grass sward on total canopy water and carbon fluxes of the Le-Bray forest (Les-Landes, Southwestern France). The Le-Bray forest consists of maritime pine and an herbaceous undergrowth (purple moor-grass), which is characterised by a low stomatal control of transpiration, in contrast to maritime pine. $\mathrm{A} \mathrm{CO}_{2}$-responsive land surface model is used that includes responses of woody and herbaceous species to water stress. An attempt is made to represent the properties of the undergrowth vegetation in the land surface model Interactions between Soil, Biosphere, and Atmosphere, $\mathrm{CO}_{2}$-responsive, ISBA-A-g $\mathrm{g}_{s}$. The new adjustment allows for a fairly different environmental response between the forest canopy and the understory in a simple manner. The model's simulations are compared with long term (1997 and 1998) micro-meteorological measurements over the Le-Bray site. The fluxes of energy, water and $\mathrm{CO}_{2}$, are simulated with and without the improved representation of the undergrowth vegetation, and the two simulations are compared with the observations. Accounting for the undergrowth permits one to improve the model's scores. A simple sensitivity experiment shows the behaviour of the model in response to climate change conditions, and the understory effect on the water balance and carbon storage of the forest. Accounting for the distinct characteristics of the undergrowth has a substantial and positive effect on the model accuracy and leads to a different response to climate change scenarios.
\end{abstract}

Key words. Hydrology (Surface processes; Soil moisture; Evapotranspiration)

\section{Introduction}

In the past few years, an increasing number of longterm studies on the energy and mass exchange between forest canopies and the atmosphere have been conducted

Correspondence to: J.-Ch. Calvet

(jean-christophe.calvet@meteo.fr)
(Tenhunen et al., 1998; Valentini et al., 1999; Wilson and Baldocchi, 2000; Wilson et al., 2001; Anthoni et al., 2002). These data represented an opportunity to test and modify Soil-Vegetation-Atmosphere Transfer (SVAT) schemes, and, in particular, to study the vegetation response to various climatic conditions in terms of the heat, water and carbon budget (Baldocchi and Wilson, 2001). These long- term measurements also allowed for the investigation of the modelling of biological processes like photosynthesis, transpiration, plant growth, and vegetation sensitivity to climatic events (drought in particular). The SVAT scheme ISBA-A$\mathrm{g}_{s}$ (Calvet et al., 1998) is a version of the ISBA land surface model (Noilhan and Planton, 1989; Noilhan and Mahfouf, 1996) of Météo-France, coupled with an A-g $\mathrm{g}_{s}$ (Appendix A) photosynthesis model (Jacobs et al., 1996). In ISBA-A-g the net photosynthetic assimilation $\left(A_{n}\right)$ response to environmental factors is modelled in a rather mechanistic way and the stomatal conductance $\left(g_{s}\right)$ is derived from $A_{n}$ (Collatz et al., 1991). ISBA-A-g $\mathrm{g}_{s}$ is a research SVAT scheme used in the atmospheric model Meso-NH (Lafore et al., 1998).

In a previous study, the ISBA-A-g $\mathrm{g}_{s}$ model was improved in terms of water balance and plant response to water stress: in Calvet et al. (2004) the water stress parameterisation proposed for herbaceous species by Calvet (2000) was adapted to the case of woody plants. A large number of data were used to determine the response of woody species to soil moisture stress. In particular, the leaf-scale measurements performed by Picon et al. (1996) over two tree species, presenting contrasting responses to drought (maritime pine Pinus pinaster - and sessile oak - Quercus petraea), were employed. In response to water stress, maritime pine presented higher values of the water use efficiency (WUE), a drought-avoiding strategy, while sessile oak presented little change in WUE, a drought-tolerant strategy.

In this study, we performed, for the first time, a detailed validation of the model by using long time series of measured water vapour and $\mathrm{CO}_{2}$ fluxes. In particular, we attempted to determine to what extent the hypothesis of homogeneous leaf properties could be used in ISBA-A-g $\mathrm{g}_{s}$. The response to soil moisture stress presented in Calvet et al. (2004) was used in ISBA-A-g $\mathrm{g}_{s}$ and the simulations were compared to measured 
Table 1. The ISBA scheme soil and vegetation structure parameters over the Le-Bray forest. The values are either prescribed, measured, or calibrated.

\begin{tabular}{|c|c|c|c|}
\hline Symbol & Definition & Value & Source \\
\hline \multicolumn{4}{|c|}{ Soil parameters } \\
\hline$d_{2}$ & Soil root-zone depth & $0.8 \mathrm{~m}$ & Measured - Ogée et al., 2003 \\
\hline$C L A Y$ & Clay fraction & $2 \%$ & Measured - Ogée et al., 2003 \\
\hline$S A N D$ & Sand fraction & $98 \%$ & Measured - Ogée et al., 2003 \\
\hline$w_{\text {wilt }}$ & Wilting point & $0.03 \mathrm{~m}^{3} \mathrm{~m}^{-3}$ & Measured - Loustau et al., 1990 \\
\hline$w_{f c}$ & Field Capacity & $0.17 \mathrm{~m}^{3} \mathrm{~m}^{-3}$ & Measured - Loustau et al., 1990 \\
\hline$w_{\text {sat }}$ & Saturation & $0.43 \mathrm{~m}^{3} \mathrm{~m}^{-3}$ & Measured - Berbigier et al., 2001 \\
\hline$C_{3}$ & Drainage coefficient & 0.012 & Calibrated - Ogée et al., 2001 \\
\hline \multicolumn{4}{|c|}{ Vegetation parameters } \\
\hline$h$ & Vegetation height & $18 \mathrm{~m}$ & Measured - Berbigier et al., 2001 \\
\hline veg & Vegetation coverage & $100 \%$ & Prescribed \\
\hline$\alpha$ & Albedo & 0.11 & Measured - Berbigier et al., 2001 \\
\hline$\varepsilon_{s}$ & Emissivity & 0.98 & Prescribed \\
\hline$C_{v}$ & Thermal coefficient & $1.2 \times 10^{-5} \mathrm{~K} \mathrm{~m}^{-2} \mathrm{~J}^{-1}$ & Calibrated - Sect. 2.6 \\
\hline$z_{0}$ & Roughness length & $2.0 \mathrm{~m}$ & Measured - Ogée et al., 2003 \\
\hline $\ln \left(z_{0} / z_{0 h}\right)$ & $k B^{-1}$ term & 3 & Measured - Lagouarde et al., 1994 \\
\hline$d$ & Displacement height & $16.6 \mathrm{~m}$ & Measured - Ogée et al., 2003 \\
\hline
\end{tabular}

fluxes at one FLUXNET (Valentini et al., 1999) long-term site in France: the Le-Bray forest (maritime pine - Pinus pinaster). The Le-Bray forest data set permitted one to assess different parameterisations of the biological processes, and to simulate the canopy energy, water and carbon balance. In particular, the Le-Bray forest presents a separate grass understory, and an intercomparison of two versions of ISBA-A- $\mathrm{g}_{s}$, with and without a representation of distinct leaf characteristics of trees and grass, was performed. Finally, a sensitivity study was carried out with the Le-Bray forest site data in order to investigate the effect of climate change on water budget, net assimilation and net ecosystem exchange of $\mathrm{CO}_{2}$.

\section{Material and methods}

In this section, the data are presented, as well as the methods we used in order to:

- characterise the canopy response to water stress (either modelled or observed),

- model the specific characteristics of the undergrowth vegetation,

- model the specific soil drainage properties of Le-Bray,

- characterise the energy transfer within the vegetation canopy,

- model the ecosystem respiration,

- assess the model accuracy.
The simulations performed by ISBA-A-g $\mathrm{g}_{s}$ are presented and analysed in Sect. 3.

\subsection{The Le-Bray site}

In this study, the maritime pine forest of Le-Bray was studied for two annual cycles (1997 and 1998). The measurements were performed by INRA-Bordeaux. Table 1 summarizes the soil and vegetation parameters of the forest. The Le-Bray site (Berbigier et al., 2001) is located in the Les-Landes forest at about $20 \mathrm{~km}$ from Bordeaux $\left(44^{\circ} 42 \mathrm{~N}, 0^{\circ} 46 \mathrm{~W}\right.$, altitude $62 \mathrm{~m}$ ). The Le-Bray forest consists of a maritime pine stand of about 30 years and $18-19 \mathrm{~m}$ tall. The forest canopy exhibits two well-separated foliage layers. The upper one, between 12 and $18 \mathrm{~m}$, consists of tree crowns with a maximum leaf area index (LAI) of $2.8 \mathrm{~m}^{2} \mathrm{~m}^{-2}$. The undergrowth forms the lowest layer and consists of purple moor-grass (Molinia coerulea L. Moench). The purple moor-grass is perennial but the leaves are green only from April to September, with a maximum LAI and height of $1.45 \mathrm{~m}^{2} \mathrm{~m}^{-2}$ and $0.7 \mathrm{~m}$, respectively (Loustau and Cochard, 1991). The resulting total green LAI varies between $1.8 \mathrm{~m}^{2} \mathrm{~m}^{-2}$ in winter and $4.2 \mathrm{~m}^{2} \mathrm{~m}^{-2}$ in summer (Porté, 1999; Ogée et al., 2003). It reaches its maximum value in August and, during this period, the purple moor-grass LAI represents one-third of the total LAI (Fig. 1). The soil is a sandy hydromorphic podzol and a compact sandlayer called Alios is found at a depth of about $0.8 \mathrm{~m}$. The hardness and chemical composition of this layer makes it barely penetrable by the roots, so that the extractable water content is low (about $115 \mathrm{~mm}$ ). The soil moisture variation (Fig. 1) was measured above the Alios layer. Because of the low hydraulic conductivity of the Alios layer, the vertical 

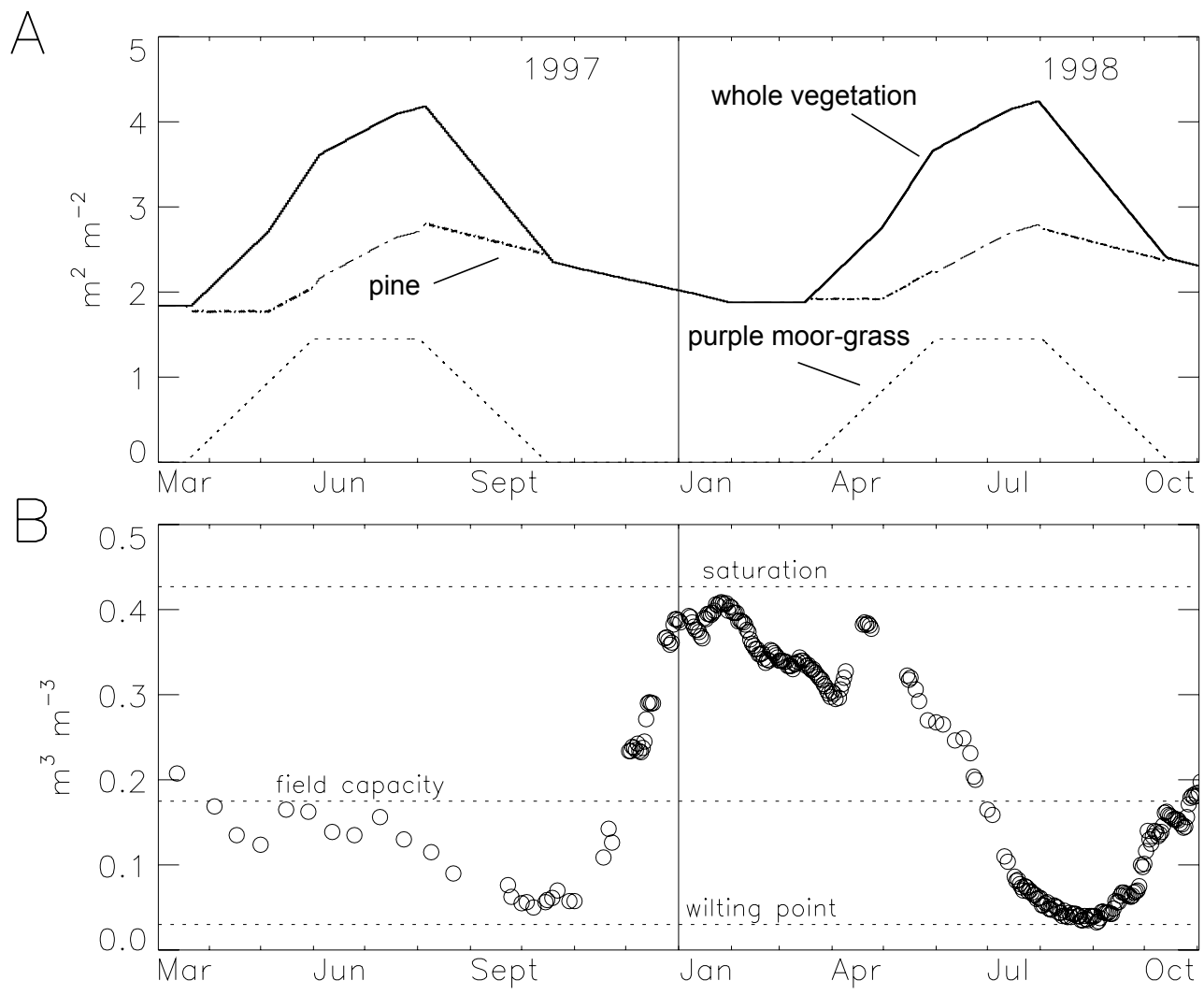

Fig. 1. Observed (A) leaf area index (LAI) and (B) root-zone soil moisture for Le-Bray. The Le-Bray LAI is the sum of the pine and purple moor-grass LAI (long- and short- dashed lines, respectively). Soil moisture measurements concern the $0.8 \mathrm{~m}$ soil column.

drainage is limited (Ogée and Brunet, 2002), and during winter and spring, the soil water content is generally above field capacity. During the two winters of the study, the water table level reached the soil surface. However, 1998 was drier than 1997 (the cumulative annual precipitation was 846 and $998 \mathrm{~mm}$, respectively). The average annual precipitation and air temperature for this site are $930 \mathrm{~mm}$ and $12.5^{\circ} \mathrm{C}$, respectively.

\subsection{Micro-meteorological observations}

Eddy fluxes of momentum, sensible heat $(H)$, water vapour $(E)$ and $\mathrm{CO}_{2}\left(F_{c}\right)$ were measured above the tree crown at 25 and $18 \mathrm{~m}$ above ground (Berbigier et al., 2001), as well as net radiation $\left(R_{n}\right)$. Heat storage terms (air, vegetation and soil) were estimated from temperature profiles measured by thermocouples placed at different levels in the soil and in the canopy. The meteorological variables (precipitation, solar radiation $R_{g}$, air temperature $T_{a}$, relative humidity $q_{a}$, and wind speed) were monitored on a 30-min basis. Surface infrared temperature, atmospheric pressure and atmospheric downward long-wave radiation $\left(R_{a}\right)$ were measured.

\subsection{Comparing leaf and canopy responses to water stress}

The parameterisation of soil moisture stress (Appendix B) obtained by Calvet et al. (2004) from leaf-level gas-exchange measurements performed by Picon et al. (1996) was employed to analyse the micrometeorological FLUXNET data,

- by implementing the improved leaf-level A-g $\mathrm{g}_{s}$ parameterisation in the ISBA-A-g $\mathrm{g}_{s}$ model of the canopy,

- by comparing the response of the leaf- to canopy-level stomatal conductances ( $g_{s}$ and $g_{s}^{\prime}$, respectively), either observed or modelled, to leaf- and canopy-to-air saturation deficits ( $D_{s}$ and $D_{s}^{\prime}$, respectively), and to the soil moisture availability.

In order to assess the effect of the purple moor-grass undergrowth on the Le-Bray forest, the leaf-level A-g module (producing $g_{s}-D_{s}$ relationships) was compared with the canopy-level observations of Le-Bray and with the canopylevel simulations of ISBA-A-g $\mathrm{g}_{s}$ (producing $g_{s}^{\prime}-D_{s}^{\prime}$ relationships). The technique employed to obtain $g_{s}^{\prime}-D_{s}^{\prime}$ relationships at the canopy scale, for various soil moisture conditions, is described in Appendix C. All the micrometeorological measurements required to perform a $g_{s}^{\prime}-D_{s}^{\prime}$ analysis at the canopy scale (heat and water vapour fluxes, surface temperature, air temperature and humidity, LAI) were available for Le-Bray. The parameters of the A- $\mathrm{g}_{s}$ module are the unstressed mesophyll conductance at $25^{\circ} \mathrm{Cg}_{m} *$, the maximum ratio between the intercellular and the atmospheric $\mathrm{CO}_{2}$ concentration $f_{o}{ }^{*}$, the maximum leaf-to-air 
Table 2. Typical values of the variables of the A-gs model for $\mathrm{C} 3$ plants, and temperature response. Note that $\varepsilon_{0}$ is the maximum quantum use efficiency, $\Gamma$ the compensation point, $A_{m, \max }$ the maximum net assimilation of the leaf, and $g_{m}$ the mesophyll conductance (* denotes unstressed soil moisture conditions). The temperature dependence of $\Gamma$ is described by means of a $Q_{10}$ response function $X\left(T_{S}\right)=X(@ 25) Q_{10}^{\left(T_{S}-25\right) / 10} . T_{1}$ and $T_{2}$ denote temperatures that enable a description of temperature inhibition characteristics: $X\left(T_{S}\right)=X(@ 25) Q_{10}^{\left(T_{S}-25\right) / 10}\left\{\left[1+\exp \left\{0.3\left(T_{1}-T_{S}\right)\right\}\right]\right.$ $\left.\left[1+\exp \left\{0.3\left(T_{S}-T_{2}\right)\right\}\right]\right\}^{-1}$, where $X\left(T_{S}\right)$ and $X(@ 25)$ are the values of the variables corresponding to the leaf temperatures $T_{S}$ and $25^{\circ} \mathrm{C}$, respectively.

\begin{tabular}{lllll}
\hline Parameter $(\mathrm{X})$ & $X_{25}$ & $Q_{10}$ & $T_{1}\left({ }^{\circ} \mathrm{C}\right)$ & $T_{2}\left({ }^{\circ} \mathrm{C}\right)$ \\
\hline$\varepsilon_{0}\left(\mathrm{mg} \mathrm{J}^{-1} \mathrm{PAR}\right)$ & 0.017 & - & - & - \\
$\Gamma\left(\mu \mathrm{mol} \mathrm{mol}^{-1}\right)$ & 45 & 1.5 & - & - \\
$A_{m, \max }\left(\mathrm{mg} \mathrm{m}^{-2} \mathrm{~s}^{-1}\right)$ & 2.2 & 2.0 & 8 & 38 \\
$g_{m}$ or $g_{m} *\left(\mathrm{~mm} \mathrm{~s}^{-1}\right)$ & $X_{25}$ & 2.0 & 5 & 36 \\
\hline
\end{tabular}

saturation deficit $D_{\max } *$, the cuticular (or minimum) conductance $g_{c}$ and the critical extractable soil moisture $\theta_{C}$. The corresponding parameter values for maritime pine are (Calvet et al., 2004) $1.58 \mathrm{~mm} \mathrm{~s}^{-1}, 0.61,100 \mathrm{~g} \mathrm{~kg}^{-1}, 0 \mathrm{~mm} \mathrm{~s}^{-1}$, and 0.10 , respectively. These values are listed in Table 3 .

\subsection{Modelling the undergrowth effect}

Previous studies have shown that the Le-Bray purple moorgrass undergrowth represents about $1 / 3$ of the summertime total LAI and contributes $1 / 3$ of the total stand evapotranspiration (Loustau and Cochard, 1991), whereas only $20 \%$ of the incident PAR reaches the undergrowth (Hassika et al., 1997).

In ISBA-A-g ${ }_{s}$, the effect of PAR extinction by the vegetation canopy is accounted for by using a simple radiative transfer model and by integrating $A_{n}$ and $g_{s}$ over the vertical. A homogeneous leaf vertical distribution is assumed and the integration is performed by using a Gauss three-point quadrature (Calvet et al., 1998). In order to account for the specific behaviour of the undergrowth, different leaf properties were prescribed:

- at the two highest integration Gauss levels (Appendix D) of the radiative transfer module of ISBA$\mathrm{A}-\mathrm{g}_{s}$, the parameters of maritime pine were prescribed in the $\mathrm{A}-\mathrm{g}_{s}$ module, using the woody drought-avoiding strategy described in Calvet et al. (2004),

- at the lowest Gauss level both the herbaceous droughttolerant and drought-avoiding strategies were tested, with specific parameters corresponding to purple moorgrass.

This new version of ISBA-A- $\mathrm{g}_{s}$ is described in Appendix D. This simple and pragmatic method allowed us to account for undergrowth vegetation while using a single-layer SVAT model. These changes only affected the computation of net assimilation and stomatal conductance; other variables of the ISBA-A-g $g_{s}$ model, like surface temperature, $\mathrm{CO}_{2}$ concentration or saturation deficit, remained representative for the whole canopy.

Purple moor-grass is characterised by a large value of the minimum conductance $g_{c}$. The $g_{c}$ value given by Kerstiens (1996) for this species is more than $1 \mathrm{~mm} \mathrm{~s}^{-1}$ (Table 3). This value is consistent with the high values of leaf conductance observed by Loustau and Cochard (1991) for the Le-Bray forest undergrowth, during dry periods characterised by high $D_{s}$ values. Several simulations were made with the modified ISBA-A-g $\mathrm{g}_{s}$, in order to estimate the other A-g $\mathrm{g}_{s}$ parameters of the undergrowth $\left(g_{m}^{*}, D_{\max }^{*}, \theta_{C}\right)$. The effect of soil moisture on the $g_{m}$ and $D_{\max }$ variables was described by using the parameterisation proposed by Calvet (2000) for $\mathrm{C}_{3}$ herbaceous plants. The drought-tolerant response of $g_{s}$ and $A_{n}$ to soil water stress was found to provide better results than the drought-avoiding strategy. The following unstressed parameters were used (Table 3): $g_{m}^{*}=1.79 \mathrm{~mm} \mathrm{~s}^{-1}$ (at a temperature of $\left.25^{\circ} \mathrm{C}\right), D_{\text {max }}^{*}=19 \mathrm{~g} \mathrm{~kg}^{-1}$, with a value of $\theta_{C}$ of 0.3 . The low value of $D_{\max }^{*}$ obtained for purple moor-grass (Table 3 ) is characteristic of a high sensitivity of stomatal aperture to leaf-to-air saturation deficit, as opposed to the low sensitivity of the water use efficiency to the soil water stress, characteristic of a drought-tolerant strategy. The other parameters of the $\mathrm{A}-\mathrm{g}_{s}$ model listed in Table 2, were prescribed according to typical values given in Calvet et al. (1998) for $\mathrm{C}_{3}$ plants.

\subsection{Modelling the Alios effect}

The Le-Bray soil moisture evolution is driven, to a large extent, by the presence of a near-surface water table in winter, due to the Alios layer (Sect. 2.1) acting as an obstacle to drainage at the bottom of the root zone. Consequently, the effective soil hydraulic conductivity for Le-Bray (Delpech, 1996) is much smaller $\left(0.28 \mathrm{~m} \mathrm{~d}^{-1}\right)$ than for a usual sandy soil $\left(15 \mathrm{~m} \mathrm{~d}^{-1}\right)$. In such conditions, the texture-driven value of the drainage coefficient $C_{3}$ proposed by Noilhan and Planton (1989) and used in the ISBA-A-g g $_{s}$ model was not applicable and had to be calibrated. Drainage was not measured at Le-Bray but it was the only unknown term of the water balance equation. The available measurements of precipitation, evapotranspiration, and soil water content, were used by Ogée et al. (2001) to estimate the $C_{3}$ parameter: $C_{3}=0.012$ (Table 1), a value about 215 times lower than the ISBA value for a sandy soil.

\subsection{Forest heat transfer parameters}

The vegetation heat transfer coefficient $C_{v}$ used in the ISBA model and the logarithmic ratio between momentum and heat roughness lengths ( $z_{0}$ and $z_{0 h}$, respectively), also called $k B^{-1}$, had to be estimated. For open canopies, an empirical value of $k B^{-1}=2.3$ is often assumed, but significantly higher values were obtain by calibration (Calvet et al., 1998) 
Table 3. Values of the parameters for the trees and undergrowth of Le-Bray.

Note that $g_{m}$ is the mesophyll conductance, $f_{0}$ the maximum potential value of the ratio between internal and external leaf concentration of $\mathrm{CO}_{2}, D_{\max }$ the maximum value of air saturation deficit (* denotes unstressed soil moisture conditions), $g_{c}$ the leaf cuticular conductance and $\theta_{c}$ the critical extractable soil moisture.

\begin{tabular}{|c|c|c|c|c|c|c|c|}
\hline Plant species & $\begin{array}{l}g_{m} * \\
\left(\mathrm{~mm} \mathrm{~s}^{-1}\right)\end{array}$ & $f_{0} *$ & $\begin{array}{l}D_{\max } * \\
\left(\mathrm{~g} \mathrm{~kg}^{-1}\right)\end{array}$ & $g_{c}$ & $\begin{array}{l}\theta_{c} \\
\left(\mathrm{~mm} \mathrm{~s}^{-1}\right)\end{array}$ & $\begin{array}{l}\text { Response to soil } \\
\text { moisture stress }\end{array}$ & Source \\
\hline Maritime pine & 1.58 & 0.61 & 100 & 0.0 & 0.10 & Drought-avoiding $^{\mathrm{a}}$ & Calvet et al., 2004 \\
\hline Purple moor-grass & 1.79 & 0.95 & 19 & 1.07 & 0.30 & Drought-tolerant ${ }^{\mathrm{b}}$ & $\begin{array}{l}\text { Kerstiens (1996) for } g_{c} \\
\text { Optimisation of the } \\
\text { model's score on fluxes } \\
\text { for the other parameters }\end{array}$ \\
\hline
\end{tabular}

\footnotetext{
${ }^{a}$ Stress response for woody species by Calvet et al., 2004
}

b Stress response for herbaceous species by Calvet, 2000
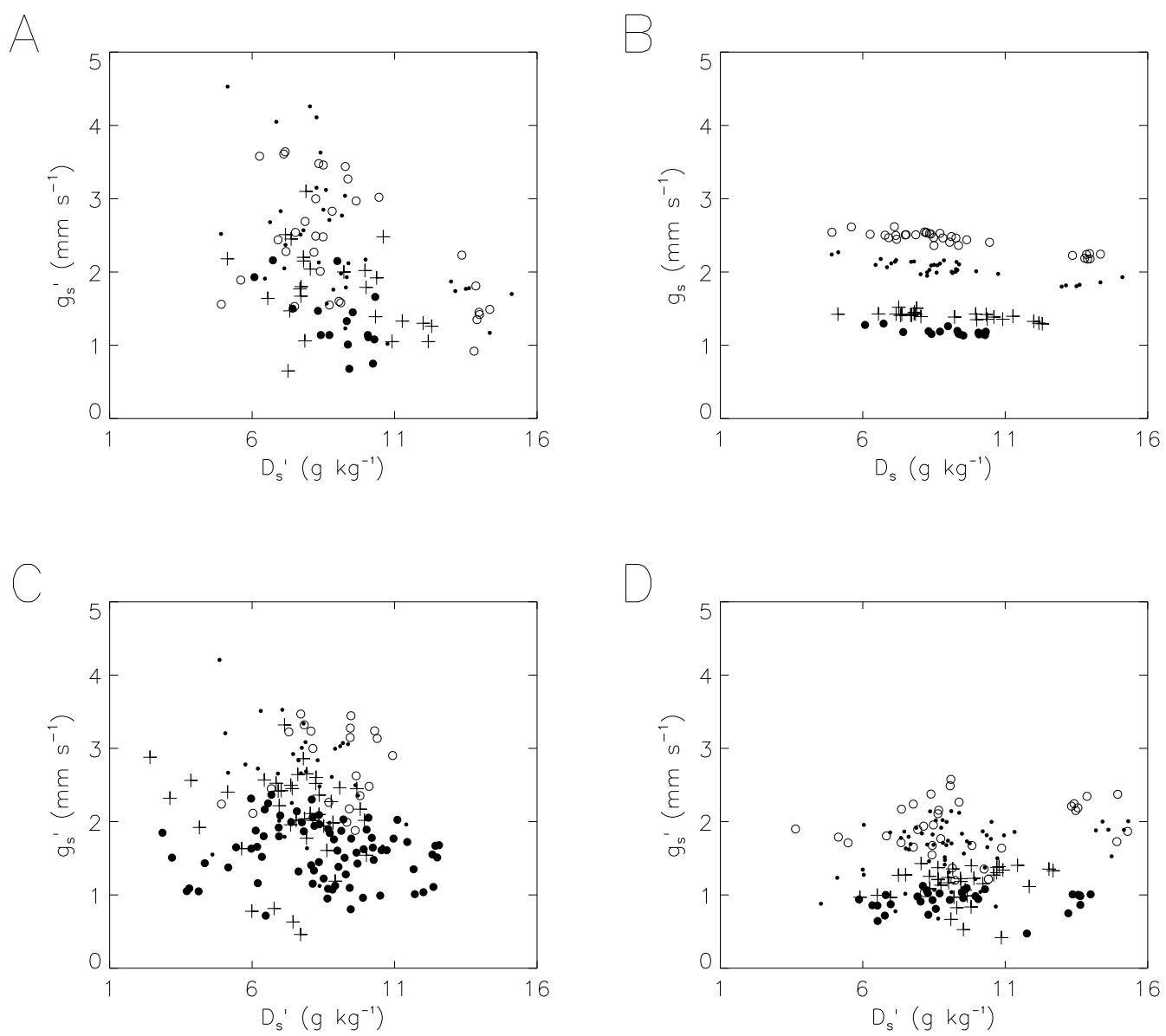

Fig. 2. Observed and simulated stomatal conductance of the Le-Bray forest versus leaf-to-air saturation deficit, for various soil moisture conditions: values of the normalised extractable soil moisture content, comprised in the intervals $0.10-0.25,0.30-0.45,0.70-0.80$, 0.9-1.0 (solid circles, pluses, points, and open circles, respectively). (A, C, D) Canopy-level conductance $g_{s}^{\prime}$ vs. effective leaf-to-air saturation deficit $D_{s}^{\prime},(\mathbf{B})$ leaf-scale $g_{s}$ vs. $D_{s}$. The observed and simulated estimates were obtained from (A) micrometeorological measurements of Berbigier et al. (2001), (B) leaf-scale simulations by the A-g model using the Picon drought-avoiding parameterisation $\left(g_{m}^{*}=1.58 \mathrm{~mm} \mathrm{~s}^{-1}, f_{0}^{*}=0.61, D_{\max }=100 \mathrm{~g} \mathrm{~kg}^{-1}, \theta_{c}=0.10\right)$, and from ISBA-A-g $\mathrm{g}_{s}$ simulations using the Picon drought-avoiding parameterisation, considering (C) a representation of the purple moor-grass undergrowth in the pine forest, or (D) a single layer of maritime pine. The $g_{s}^{\prime}$ and $D_{s}^{\prime}$ values were obtained by using the method described in Appendix C, for both the model (C, D) and the observations (A). 
or experimental measurements (Verhoef et al., 1997). A value of 3, consistent with measurements of Lagouarde et al. (1994) over Le-Bray, was used in our simulations.

The parameter $C_{v}$ was estimated by minimizing the rms error between simulated and observed half-hourly averaged total storage flux (in the ground and in different compartments of the canopy) given by Lamaud et al. (2001). The optimal value $C_{v}=1.2 \times 10^{-5} \mathrm{~K} \mathrm{~m}^{-2} \mathrm{~J}^{-1}$, is similar to the value, found by Delire et al. (1997) for an Amazonian forest site.

\subsection{Estimating the ecosystem respiration}

In-situ eddy correlation measurements provided half-hourly estimates of the net $\mathrm{CO}_{2}$ flux, $F_{c}$ (in this study, positive values of $F_{c}$ correspond to a downward flux), representing the difference between ecosystem gross primary production $A_{g}$ (i.e. the sum of net assimilation $A_{n}$ and autotrophic dark respiration $R_{d}$ ) and the ecosystem respiration $R_{e}$ :

$F_{c}=A_{g}-R_{e}$.

The $R_{e}$ values were estimated with nighttime net $\mathrm{CO}_{2}$ fluxes on turbulent nights (friction velocity $u^{*}>0.4$ ) by Berbigier et al. (2001). The obtained expression is given by Eq. (2), in units of $\mathrm{mg} \mathrm{CO}_{2} \mathrm{~m}^{-2} \mathrm{~s}^{-1}$ :

$R_{e}=0.0422 \exp \left(0.105 T_{\text {Soil }-L B}\right)$,

where $T_{\text {Soil }-L B}$ represents the in-situ surface soil temperature $\left({ }^{\circ} \mathrm{C}\right)$, at the soil-litter interface (Berbigier at al., 2001). In order to account for the difference between $T_{\text {Soil }-L B}$ and the soil temperature values $\left(T_{2}\right)$ produced by ISBA-A- $\mathrm{g}_{s}$, a $Q_{10}$ temperature-response function was used to represent $R_{e}$ in ISBA-A-g :

$R_{e}=R_{e 25} \cdot Q_{10}^{(T 2-25) / 10}$.

Best-fit $R_{e 25}$ and $Q_{10}$ parameters of Eq. (3) were obtained by minimizing the rms error between the $R_{e}$ estimates given by Eq. (2), based on the measured $T_{\text {Soil }-L B}$, and the values of $R_{e}$ given by Eq. (3), based on the modelled $T_{2}$. Equation (3) was found to be a good approximation of Eq. (2), with rms errors less than $0.03 \mathrm{mg} \mathrm{CO}_{2} \mathrm{~m}^{-2} \mathrm{~s}^{-1}$, and a square correlation coefficient value higher than 0.85 . The $R_{e 25}$ value of Eq. (3) obtained for Le-Bray was $0.39 \mathrm{mg} \mathrm{CO}_{2} \mathrm{~m}^{-2} \mathrm{~s}^{-1}$, with a $Q_{10}$ value of 2.22 .

\subsection{Model statistics}

The employed statistics to assess the model performance were the rms difference, the mean bias, and the skill score. The model skill score $E f$ (or Nash criterium) is defined as:

$E f=1-\frac{\sum_{i}\left(x_{i O B S}-x_{i M O D}\right)^{2}}{\sum_{i}\left(x_{i O B S}-\overline{x_{O B S}}\right)^{2}}$,

where $x$ are the values of the considered variable, either measured or simulated (OBS and $M O D$ subscripts, respectively). A value of $E f$ of 1 corresponds to a perfect simulation and values of $E f$ close to 0 correspond to a basic representation of $x$ by its constant average value. Values of $E f$ lower than about 0.2 show that the model is not adequate.

\section{Results}

The ISBA-A-g $\mathrm{g}_{s}$ model simulations for the Le-Bray forest were performed for the two years 1997 and 1998, by using the parameters given in Tables 1-3. The model was run by prescribing the LAI series presented in Fig. 1. An adaptation of ISBA-A-g $\mathrm{g}_{s}$ to the presence of a contrasting vegetation undergrowth (Sect. 2.4) was used, and the stomatal behaviour of the pines was described by using the results of Calvet et al. (2004) at the leaf level.

\subsection{Undergrowth contribution for Le-Bray}

The purple moor-grass undergrowth had a pronounced effect on the canopy conductance $g_{s}^{\prime}$. This conclusion was derived from the analysis of the relationship between $g_{s}^{\prime}$ and $D_{s}^{\prime}$, either observed or modelled. For optimal PAR and temperature conditions, $g_{s}^{\prime}$ depends mainly on water stress, i.e. on atmospheric humidity and on soil water availability. The water stress is represented by two variables: the canopy-level saturation deficit $D_{s}^{\prime}$ and the soil moisture index $\theta$ (Eqs. (C2) and (B1), respectively). Analysing $g_{s}^{\prime}-D_{s}^{\prime}$ relationships at contrasting values of $\theta$, is a way to characterise the canopy response to water stress.

In order to assess the stomatal sensitivity to air humidity of the Le-Bray forest for various soil moisture conditions, and the impact of the undergrowth vegetation, the canopy-level $g_{s}^{\prime}$ and $D_{s}^{\prime}$ derived from the measurements (and obtained by the method described in Sect. 2.3 and Appendix C) were compared with the $g_{s}^{\prime}$ and $D_{s}^{\prime}$ values produced by ISBA$\mathrm{A}-\mathrm{g}_{s}$, with and without the improved representation of the undergrowth vegetation. In Fig. 2a, the observed Le-Bray $g_{s}^{\prime}-D_{s}^{\prime}$ relationship, based on the micrometeorological measurements, is shown for four classes of soil moisture. The different levels of soil water stress had an effect on $g_{s}^{\prime}$ and $D_{s}^{\prime}$ : while the ordinary decrease of $g_{s}^{\prime}$, in response to increasing $D_{s}^{\prime}$, was observed, a slight but noticeable difference appeared in the relative position of stressed and unstressed conditions. However, the obtained $g_{s}^{\prime}$ and $D_{s}^{\prime}$ values disagreed with the behaviour modelled in Calvet et al. (2004), using the leaf-level measurements of Picon et al. (1996) over maritime pine (Fig. 2b). The leaf-level A-g simulations obtained by using the Picon leaf-level parameters given in Table 3 predicted a less marked response of $g_{s}$ to saturation deficit, and a clear, independent soil moisture effect. Figure $2 \mathrm{c}$ and $\mathrm{d}$ show that the difference between the model and the observations could be explained by including the undergrowth contribution in ISBA-A-g : $_{s}$ while the model response at the canopy level, considering a single layer of pine (Fig. 2d), was very similar to leaf-level simulations, accounting for the purple moor-grass layer in the model as described in Sect. 2.4 (Fig. 2c) permitted one to simulate the 
Table 4. Errors affecting the simulated Le-Bray site half-hourly outputs in 1997 and 1998 for different ISBA parameterisations in terms of rms error, mean bias (simulated minus observed), and skill score on evapotranspiration $(E)$, heat flux $(H)$, net radiation $\left(R_{n}\right)$, heat storage flux $(G)$, surface temperature $\left(T_{S}\right)$, soil water storage $\left(w_{2} \times d_{2}\right)$ and net ecosystem $\mathrm{CO}_{2}$ flux $\left(F_{c}\right)$.

\begin{tabular}{|c|c|c|c|c|c|c|c|c|}
\hline $\begin{array}{l}\text { ISBA } \\
\text { Version }\end{array}$ & $\begin{array}{l}\text { Statistics } \\
1997 / 1998\end{array}$ & $E$ & $H$ & $R_{n}$ & $G$ & $T_{S}$ & $w_{2} \times d_{2}$ & $F_{c}$ \\
\hline \multirow[t]{3}{*}{ Standard ${ }^{\mathrm{a}}$} & rms error & $38 / 38 \mathrm{~W} \mathrm{~m}^{-2}$ & $43 / 50 \mathrm{~W} \mathrm{~m}^{-2}$ & $13 / 15 \mathrm{~W} \mathrm{~m}^{-2}$ & $35 / 23 \mathrm{~W} \mathrm{~m}^{-2}$ & $1.8 / 1.0^{\circ} \mathrm{C}$ & $49 / 31 \mathrm{~mm}$ & - \\
\hline & mean bias & $3 / 2 \mathrm{~W} \mathrm{~m}^{-2}$ & $22 / 23 \mathrm{~W} \mathrm{~m}^{-2}$ & $-8 /-11 \mathrm{~W} \mathrm{~m}^{-2}$ & $-17 / 1 \mathrm{~W} \mathrm{~m}^{-2}$ & $1.2 / 0.4^{\circ} \mathrm{C}$ & $39 / 3 \mathrm{~mm}$ & - \\
\hline & skill score & $0.81 / 0.77$ & $0.75 / 0.66$ & $1 / 0.99$ & $0.33 / 0.49$ & $0.93 / 0.98$ & $0.67 / 0.92$ & - \\
\hline \multirow[t]{3}{*}{$\mathrm{A}-\mathrm{g}_{s} \mathrm{~b}$} & rms error & $43 / 48 \mathrm{~W} \mathrm{~m}^{-2}$ & $53 / 57 \mathrm{~W} \mathrm{~m}^{-2}$ & $12 / 14 \mathrm{~W} \mathrm{~m}^{-2}$ & $34 / 24 \mathrm{~W} \mathrm{~m}^{-2}$ & $1.8 / 1.2^{\circ} \mathrm{C}$ & $57 / 27 \mathrm{~mm}$ & $\begin{array}{l}0.215 / 0.212 \\
\mathrm{mg} \mathrm{m}^{-2} \mathrm{~s}^{-1}\end{array}$ \\
\hline & mean bias & $-2 /-2 \mathrm{~W} \mathrm{~m}^{-2}$ & $25 / 26 \mathrm{~W} \mathrm{~m}^{-2}$ & $-8 /-10 \mathrm{~W} \mathrm{~m}^{-2}$ & $-15 / 2 \mathrm{~W} \mathrm{~m}^{-2}$ & $1.2 / 0.6^{\circ} \mathrm{C}$ & $50 / 9 \mathrm{~mm}$ & $\begin{array}{l}0.010 / 0.029 \\
\mathrm{mg} \mathrm{m}^{-2} \mathrm{~s}^{-1}\end{array}$ \\
\hline & skill score & $0.76 / 0.63$ & $0.62 / 0.55$ & $1 / 0.99$ & $0.36 / 0.44$ & $0.93 / 0.97$ & $0.54 / 0.94$ & $0.46 / 0.47$ \\
\hline \multirow[t]{3}{*}{$\mathrm{A}-\mathrm{g}_{s}{ }^{\mathrm{c}}$} & rms error & $40 / 40 \mathrm{~W} \mathrm{~m}^{-2}$ & $43 / 46 \mathrm{~W} \mathrm{~m}^{-2}$ & $12 / 14 \mathrm{~W} \mathrm{~m}^{-2}$ & $34 / 22 \mathrm{~W} \mathrm{~m}^{-2}$ & $1.7 / 1.0^{\circ} \mathrm{C}$ & $30 / 25 \mathrm{~mm}$ & $\begin{array}{l}0.204 / 0.198 \\
\mathrm{mg} \mathrm{m}^{-2} \mathrm{~s}^{-1}\end{array}$ \\
\hline & mean bias & $8 / 8 \mathrm{~W} \mathrm{~m}^{-2}$ & $16 / 17 \mathrm{~W} \mathrm{~m}^{-2}$ & $-7 /-9 \mathrm{~W} \mathrm{~m}^{-2}$ & $-16 / 2 \mathrm{~W} \mathrm{~m}^{-2}$ & $1.1 / 0.4^{\circ} \mathrm{C}$ & $10 /-18 \mathrm{~mm}$ & $\begin{array}{l}-0.015 / 0.003 \\
\mathrm{mg} \mathrm{m}^{-2} \mathrm{~s}^{-1}\end{array}$ \\
\hline & skill score & $0.79 / 0.75$ & $0.75 / 0.71$ & $1 / 1$ & $0.38 / 0.52$ & $0.94 / 0.98$ & $0.87 / 0.95$ & $0.51 / 0.54$ \\
\hline
\end{tabular}

a ISBA (Noilhan and Mahfouf, 1996), no representation of photosynthesis, Minimum stomatal resistance $R s_{\text {min }}=200 \mathrm{~s} \mathrm{~m}^{-1}$

$\mathrm{b}^{\mathrm{b}}$ ISBA-A-g $\mathrm{g}_{s}$, one layer of maritime pine, drought-avoiding parameterisation

$\left(g_{m}^{*}=1.58 \mathrm{~mm} \mathrm{~s}^{-1}, f_{0}^{*}=0.6, D_{\max }=100 \mathrm{~g} \mathrm{~kg}^{-1}, \theta_{c}=0.1\right)$

${ }^{\mathrm{c}}$ ISBA-A-g $\mathrm{g}_{s}$, including the characteristics of the purple moor-grass undergrowth

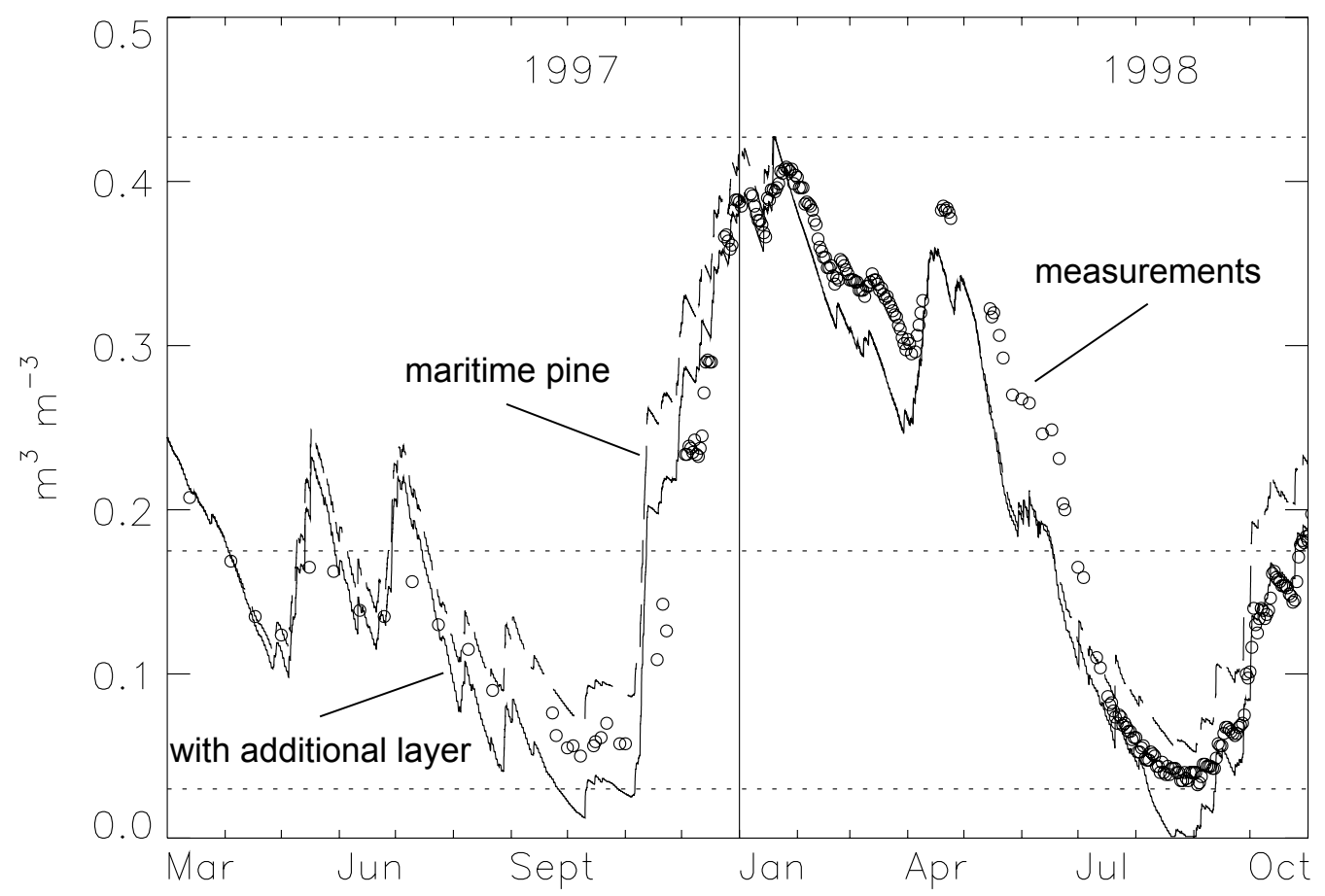

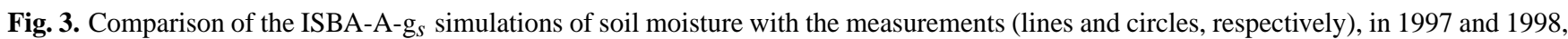
for Le-Bray. Two simulations are compared: considering a single layer of maritime pine, or a layer of maritime pine and an additional layer representing the purple moor-grass undergrowth (long-dashed and solid lines, respectively). The dashed lines indicate (from top to bottom) different soil water contents: saturation, field capacity, wilting point. Soil moisture measurements concern the $0.8 \mathrm{~m}$ soil column. 

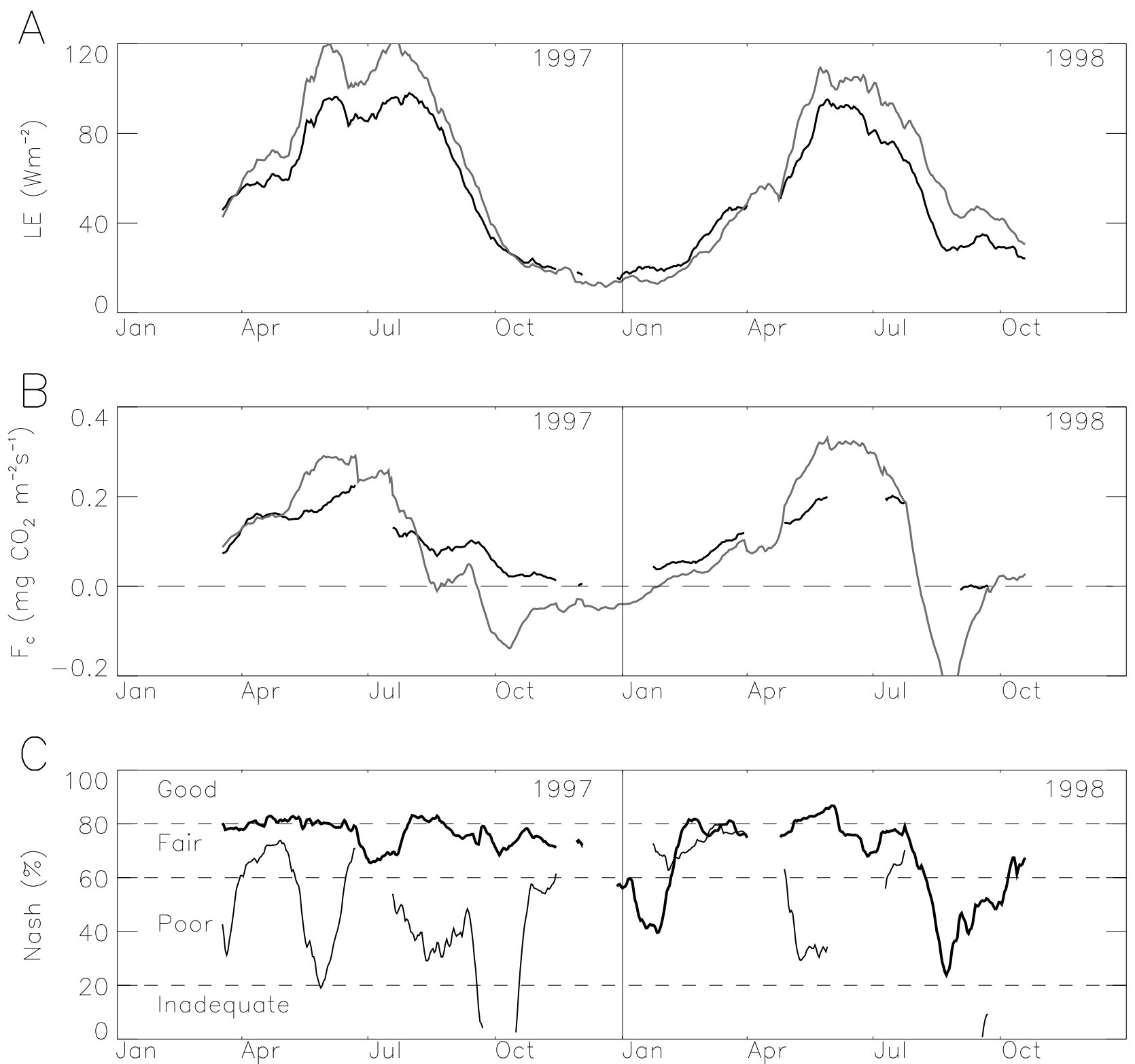

Fig. 4. Seasonal performance of the ISBA-A-g model over the Le-Bray forest, in terms of $(\mathrm{A}, \mathrm{C})$ evapotranspiration and $(\mathrm{B}, \mathrm{C})$ net $\mathrm{CO}_{2}$ flux: (A, B) comparison of simulations with eddy covariance measurements (grey and dark lines, respectively), (C) skill score (Nash criterium) for evapotranspiration and net $\mathrm{CO}_{2}$ flux (thick and fine lines, respectively). The simulated $\mathrm{CO}_{2}$ flux was obtained by using the ecosystem respiration of Berbigier et al., 2001. The flux and skill score values are smoothed using a 30-day moving average, in order to show the general trend.

increased sensitivity to saturation deficit and the lower soil moisture control which was observed over Le-Bray (Fig. 2a). Therefore, the low apparent sensitivity of the Le-Bray forest to soil moisture stress, and its apparent high sensitivity to saturation deficit, could be explained by the presence of undergrowth species presenting a large stomatal sensitivity to saturation deficit and a high minimum conductance (Table 3). Note also that the parameters of Table 3 describing the purple moor-grass denoted a high photosynthesis capacity of the undergrowth: the $g_{m} * f_{o} *$ variable, which controls the gross photosynthetic rate in the absence of stress (Calvet et al., 2004) reached $1.37 \mathrm{~mm} \mathrm{~s}^{-1}$ for the purple moor-grass, against $0.96 \mathrm{~mm} \mathrm{~s}^{-1}$ for maritime pine. Hence, accounting for the specific characteristics of the undergrowth is likely to have an impact on the simulation of the $\mathrm{CO}_{2}$ flux (see below).

\subsection{Surface water and energy budget}

In order to test the suitability of the two versions of ISBAA- $\mathrm{g}_{s}$ (with and without the properties of undergrowth vegetation), the model outputs (water vapour and heat fluxes, soil 
Table 5. Observed and simulated terms of the carbon and water budgets of the Le-Bray forest: Gross Primary Productivity (GPP), ecosystem respiration $\left(R_{e}\right)$, Net Ecosystem Exchange (NEE), evapotranspiration $(E)$, and occurrence of normalized extractable soil moisture $(\theta)$ values lower than 0.3 and 0.6. Values are presented for 1997 (from March to December) and 1998 (from January to November).

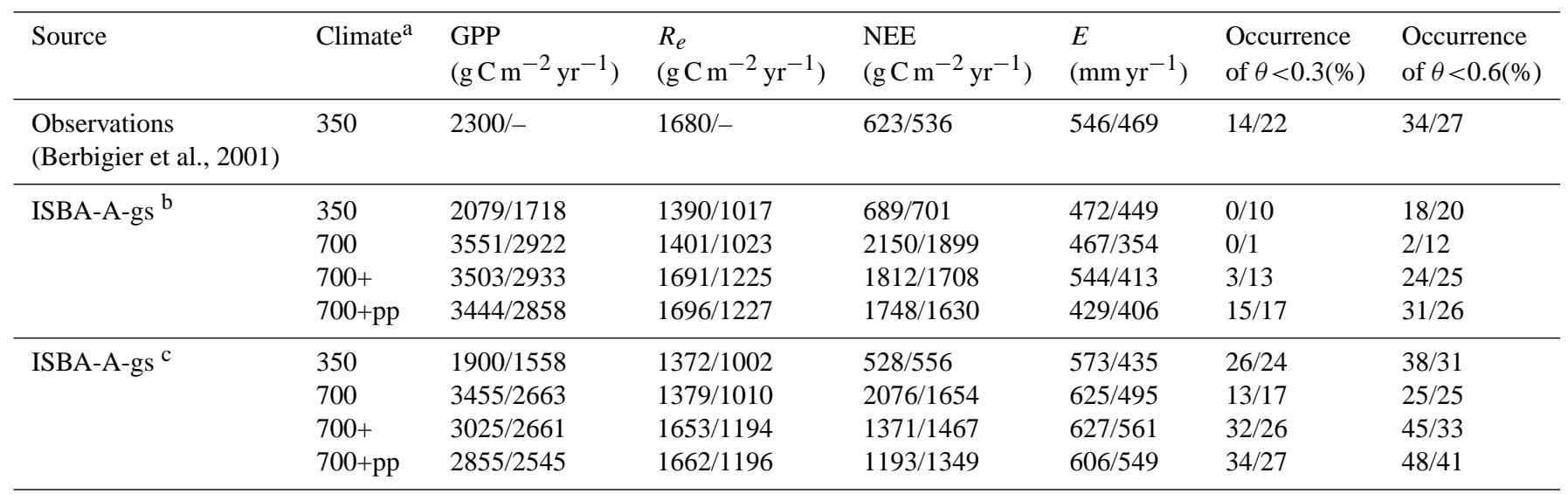

\footnotetext{
${ }^{a}$ Climate scenario: 350 stands for the observed atmospheric forcing 700 stands for a $\mathrm{CO}_{2}$-doubling scenario

$700+$ stands for a $\mathrm{CO}_{2}$-doubling scenario combined with an air temperature increase of $3^{\circ} \mathrm{C}$

$700+$ pp stands for a $\mathrm{CO}_{2}$-doubling scenario combined with an air temperature increase of $3^{\circ} \mathrm{C}$, a precipitation wintertime (DJF) increase of $40 \%$ and summertime (JJA) and autumn (SON) decrease of 10 and $20 \%$, respectively, adapted from the Southwestern Europe scenario of Déqué et al. (1998).

${ }^{\mathrm{b}}$ ISBA-A-g $_{s}$, one layer of maritime pine, drought-avoiding parameterisation $\left(g_{m}^{*}=1.58 \mathrm{~mm} \mathrm{~s}^{-1}, f_{0}^{*}=0.6, D_{\max }=100 \mathrm{~g} \mathrm{~kg}^{-1}, \theta_{c}=0.1\right)$

${ }^{\mathrm{c}}$ ISBA-A-g ${ }_{s}$, including the characteristics of the purple moor-grass undergrowth
}

moisture, and $\mathrm{CO}_{2}$ fluxes) were compared with the 2-year field measurements (Table 4). The results obtained by using the standard version of ISBA (without a description of photosynthesis nor the ability to simulate the $\mathrm{CO}_{2}$ fluxes) are presented, as well.

Accounting for the undergrowth permitted one to improve all the scores of ISBA-A-g slightly. In particular, the best simulation of soil moisture was obtained (rms error of $30 \mathrm{~mm}$ in 1997, against $49 \mathrm{~mm}$ for the standard version of ISBA), while also performing well in terms of fluxes and surface temperature. However, the model predicted soil moisture values lower than the wilting-point at the end of the summer (Fig. 3), in contradiction with the measurements performed above the compact Alios layer. This behaviour was probably caused by the simplified modelling of the undergrowth contribution which did not permit one to simulate precisely the senescence of the purple moor-grass in September (i.e. the fraction of LAI attributed to the undergrowth was overestimated by the model). The non-stomatal evaporation of the undergrowth (due to the high value of $g_{c}$ ) then triggered below wilting-point evaporation. This problem was particularly acute at the end of the summer of 1998, as shown by the fall in seasonal skill score of the model on $E$ and $F_{c}$ (Fig. 4c). Note that this poorly simulated period was part of the general trend of the model to overestimate $E$ at summertime (Fig. 4a).

\subsection{Net ecosystem $\mathrm{CO}_{2}$ exchange}

Figure 4 shows that the model skill score on $F_{c}$ was generally lower than the model skill score on $E$. In particular, $F_{c}$ was poorly simulated in some situations because the employed respiration model (Eq. 3) was probably too simple to account for the complex interaction between climate and the biological phenomena involved in the respiration. Also, owing to the nonlinear nature of Eq. (3), a small deviation of $R_{e 25}$ or $Q_{10}$ may have caused a significant bias in the estimation of the ecosystem respiration.

Accounting for the undergrowth for Le-Bray permitted one to improve the model skill score on $F_{c}$ : 0.51 for 1997 , against 0.46 without undergrowth description (Table 5). Also, the improvement was noticeable for cumulative values. Figure 5 compares the observed and the simulated cumulative carbon storage or net ecosystem exchange (NEE). The simulated NEE at Le-Bray corresponds to a large net sink of carbon (Fig. 5 and Table 5), consistent with the observations. However, the cumulative NEE, at the end of the two-year period, was overestimated by the single layer model. In spite of the high photosynthesis capacity of the undergrowth in unstressed conditions, accounting for the distinct characteristics of the undergrowth in the model simulations, triggered a decrease of about $20 \%$ in the modelled NEE (Fig. 5 and Table 5). This was caused by the higher sensitivity of the purple 


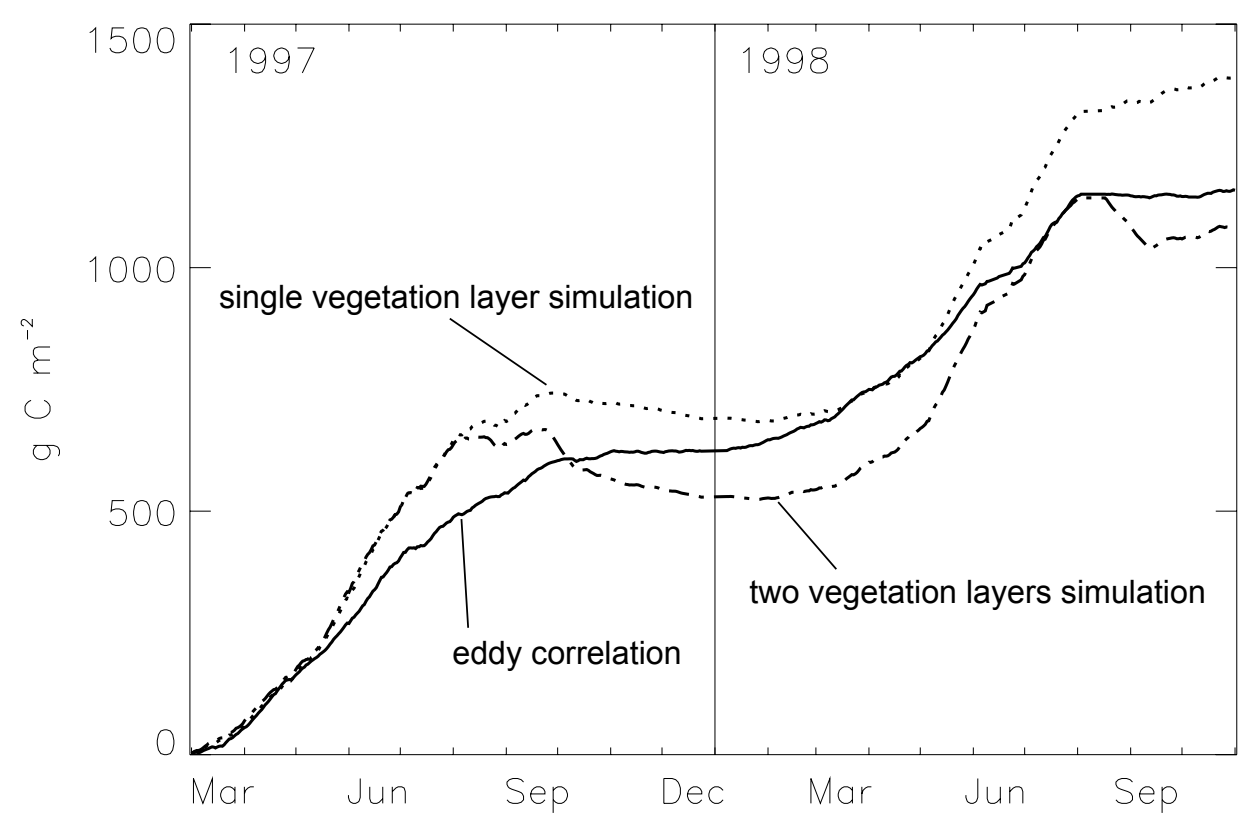

Fig. 5. The 2-year evolution of the cumulative daily net carbon storage (NEE) for the Le-Bray forest, as estimated from eddy correlation measurements and ISBA-A-g $\mathrm{g}_{s}$ simulations (solid and dotted or dashed lines, respectively). The missing half-hourly data of the observed time series (9.4\%) and the corresponding simulated values were replaced by zero values. Two simulations are displayed: assuming that the canopy consists of either a single layer of maritime pine or accounting for the characteristics of the purple moor-grass undergrowth (dotted and dash-dotted lines, respectively).
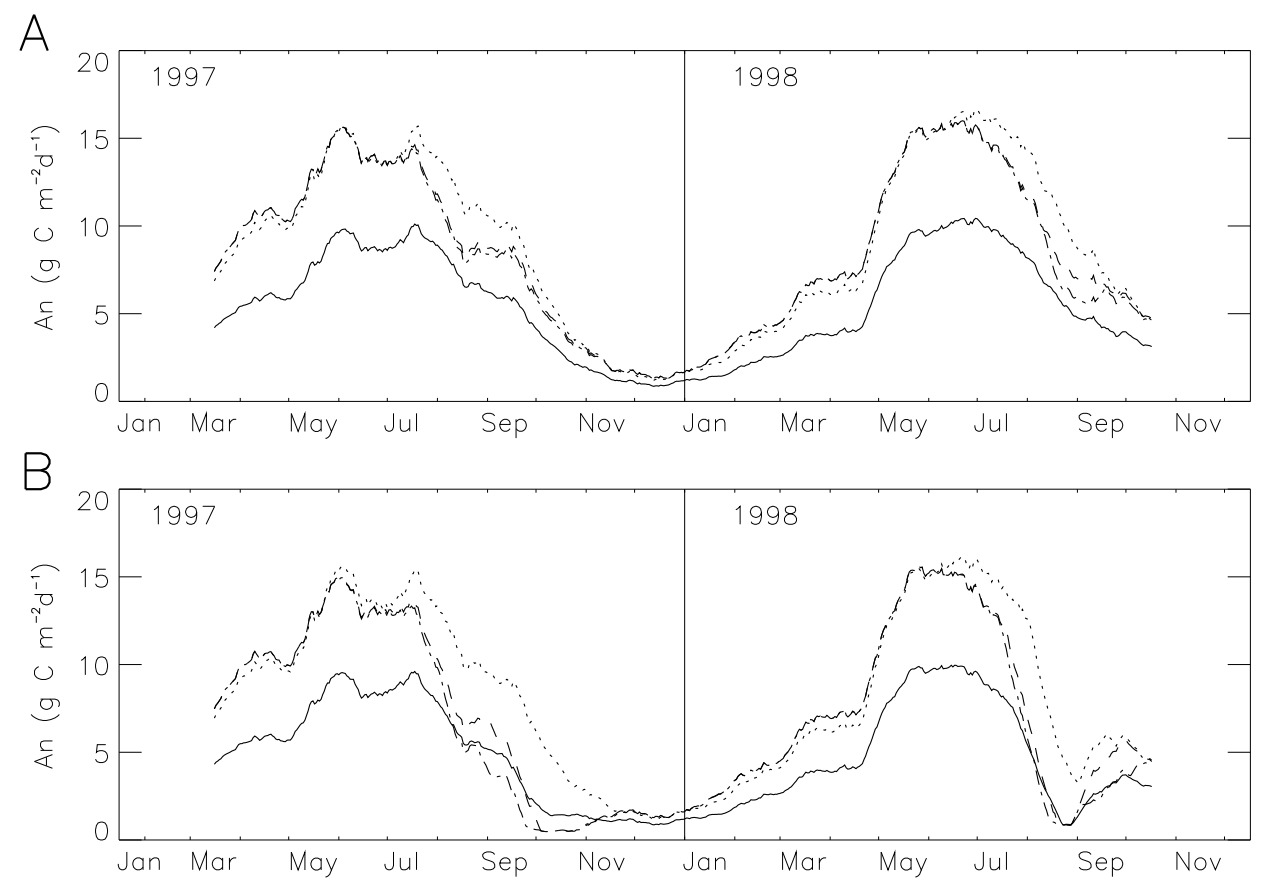

Fig. 6. Modelled leaf-net assimilation $\left(A_{n}\right)$ of Le-Bray, for different climate scenarios, 350, 700, 700+ and 700+pp (solid, dotted, dashed, and dash-dotted lines, respectively). The ISBA-A-g $\mathrm{g}_{s}$ model was run using the Picon drought-avoiding parameterisation $\left(\mathrm{gm}^{*}=1.58 \mathrm{~mm} \mathrm{~s}^{-1}\right.$, f0 $\left.*=0.6, D_{\max }=100 \mathrm{~g} \mathrm{~kg}^{-1}, \theta_{c}=0.01\right)$, considering $(\mathbf{A})$ a single layer of maritime pine, or $(\mathbf{B})$ a layer of maritime pine and an additional layer representing the purple moor-grass undergrowth. The $A_{n}$ values are smoothed using a 30-day moving average, in order to show the general trend. 

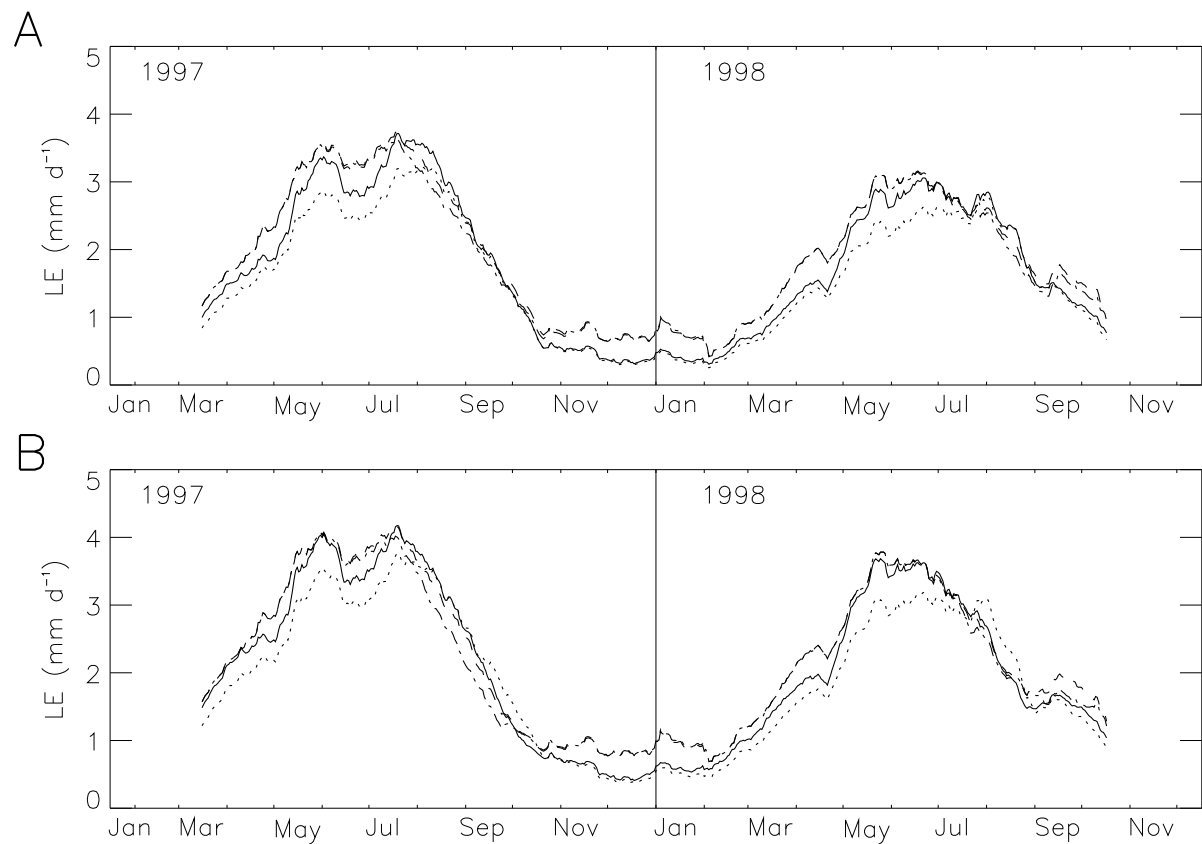

Fig. 7. Modelled ecosystem evapotranspiration $(E)$ of Le-Bray, for different climate scenarios, 350, 700, 700+ and 700+pp (solid, dotted, dashed, and dash-dotted lines, respectively). Model parameterization used for these runs are identical to those of Fig. 6, considering: (A) a single layer of maritime pine, or (B) a layer of maritime pine and an additional layer representing the purple moor-grass undergrowth. The $E$ values are smoothed using a 30 -day moving average, in order to show the general trend.

moor-grass to the air humidity deficit and by the acceleration of the soil water depletion, related to the non-stomatal evaporation of the grass. The daytime $F_{c}$ flux was overestimated by the model during the growing period and underestimated during autumn (Fig. 4). Attempts were made (not shown) to reduce the summertime overestimation of daytime $F_{c}$ by prescribing lower values of $g_{m} *$ for pines: net assimilation diminished and the skill score (Eq. (1)) on $F_{c}$ was improved. On the other hand, this correction tended to degrade the model performance in terms of mean bias and of cumulative values. In particular, the pre-existing underestimation of the annual gross primary productivity GPP (Table 5) was increased, causing a significant underestimation of NEE.

In spite of the improved description of the undergrowth, water vapour fluxes are better simulated than $\mathrm{CO}_{2}$ ones. The simplicity of the respiration model is at least partly to blame.

\section{Forest sensitivity to climate change}

A sensitivity study was performed (Table 5 and Fig. 6), in order to highlight first-order responses to climate change of the Le-Bray forest, on both water and $\mathrm{CO}_{2}$ fluxes, and the impact of the undergrowth vegetation. Three climate change scenarios (700, 700+, and 700+pp) were considered:

- $\mathrm{CO}_{2}$-doubling;

- $\mathrm{CO}_{2}$-doubling combined with an air temperature increase of $3^{\circ} \mathrm{C}$;
- $\mathrm{CO}_{2}$-doubling scenario combined with an air temperature increase of $3^{\circ} \mathrm{C}$, and a seasonal redistribution of the precipitation regime (wintertime (DJF) increase of $40 \%$, summertime (JJA) decrease of $10 \%$ and autumn (SON) decrease of $20 \%$ ), respectively.

The latter scenario $(700+p p)$ was adapted from the Southwestern Europe scenario of Déqué et al. (1998).

Irrespective of contrasting undergrowth characteristics, the simulations predicted a large effect of $\mathrm{CO}_{2}$-doubling on GPP, which increased by 50 to $70 \%$. The effect of $\mathrm{CO}_{2}$-doubling on NEE was even more dramatic (700 scenario in Table 5) but was limited by the $3^{\circ} \mathrm{C}$ warming and by the redistribution of precipitation (700+ and 700+pp scenarios). Figure 6 shows that the first-order response of leaf-net assimilation $A_{n}$ was governed by $\mathrm{CO}_{2}$-doubling (the peak value of $A_{n}$ was increased by 60 to $70 \%$ ). The $3^{\circ} \mathrm{C}$ warming tended to accelerate the growing phase of $A_{n}$ during spring.

On the other hand, the advantage of a reduction in evapotranspiration caused by $\mathrm{CO}_{2}$-doubling (Fig. 7) was lost in the 700+ and 700+pp scenarios, and the occurrence of dry periods was increased (Table 5). This phenomenon triggered the acceleration of the decreasing phase of $A_{n}$ during autumn (Fig. 6). The comparison between Figs. 6a and b shows that the purple moor-grass undergrowth was largely responsible.

Finally, prescribing in ISBA-A-g a climate change scenario, including $\mathrm{CO}_{2}$-doubling, temperature increase, and redistribution of the precipitation regime, led to the following conclusions for Le-Bray:

- An increase of GPP of about 50 to $70 \%$, 
- A marked increase of NEE of about $130 \%$,

- An increase (about 20\%) of ecosystem respiration,

- A significant increase of the annual evapotranspiration and of the occurrence of drought periods.

\section{Conclusion}

The ISBA-A-g ${ }_{s}$ SVAT model was parameterised for the LeBray forest, consisting of a coniferous species - maritime pine - and a herbaceous undergrowth. Most model parameters could be estimated from in-situ measurements rather than derived from model calibration. In particular, the physiological A-g $\mathrm{g}_{s}$ module of the model, assessed using independent leaf-level measurements and a functional parameterisation of the woody plant responses to water stress (Calvet et al., 2004), was used. This stress model was successfully applied to Le-Bray. This application study demonstrated the usefulness of introducing more complexity in the models of plant stomata response to atmospheric humidity and soil water availability: accounting for the undergrowth permitted one to improve the simulation of the surface fluxes, and rootzone soil moisture.

In a multi-layer stand like the Le-Bray forest, comprising a dense herbaceous undergrowth, the response to soil and atmospheric water stress of each canopy layer was different and had to be characterized. Note, however, that the purple moor-grass undergrowth of Le-Bray is a particularly extreme case since this species presents unusually high values of the leaf-minimum conductance.

The cumulated NEE was correctly described, although the simulated half-hourly net $\mathrm{CO}_{2}$ flux was not as good as the simulated evapotranspiration. Finally, the sensitivity of the model simulations to climate change was assessed and it was shown that accounting (or not) for the undergrowth may affect the conclusions of a climate change impact study.

\section{Appendix A \\ The A-g model}

The A- $\mathrm{g}_{s}$ approach employed to describe the leaf-scale physiological processes in ISBA-A-g $\mathrm{g}_{s}$ (Calvet et al., 1998) was the model proposed by Jacobs et al. (1996).

The photosynthesis rate in light-saturating conditions is expressed as

$A_{m}=A_{m, \max }\left[1-\exp \left\{\frac{-g_{m}^{*}\left(C_{i}-\Gamma\right)}{A_{m, \max }}\right\}\right]$.

The $g_{m} *$ variable (the unstressed mesophyll conductance) is corrected for leaf temperature using a $\mathrm{Q}_{10}$-type function, together with the maximum photosynthesis $A_{m, \max }$ and the compensation point $\Gamma$. Typical values of $A_{m, \max }$ and $\Gamma$ at a temperature of $25^{\circ} \mathrm{C}$, for $\mathrm{C}_{3}$ plants, are given in Table 2 . The internal $\mathrm{CO}_{2}$ concentration $C_{i}$ is obtained by combining the $\mathrm{CO}_{2}$ concentration at the surface of the canopy $C_{s}$ and $\Gamma$ through the following closure equation

$C_{i}=f C_{s}+(1-f) \Gamma$,

where the coupling factor $f$ is sensitive to air humidity and depends on the cuticular conductance $g_{c}$ and on $g_{m}{ }^{*}, f_{o} *$, and $D_{\text {max }}$ * by

$f=f_{0}^{*}\left(1-D_{s} / D_{\max }^{*}\right)+\left(g_{c} /\left[g_{c}+g_{m}^{*}\right]\right)\left(D_{s} / D_{\max }^{*}\right)$,

where $f_{o} *$ is the value of $f$ for $D_{s}=0 \mathrm{~g} \mathrm{~kg}^{-1}$ in unstressed conditions. The net assimilation is limited by a light deficit according to a saturation equation applied to the photosynthetically active radiation $I_{a}$ :

$A_{n}=\left(A_{m}+R_{d}\right)\left[1-\exp \left\{-\varepsilon I_{a} /\left(A_{m}+R_{d}\right)\right\}\right]-R_{d}$,

where leaf respiration is given by $R_{d}=A_{m} / 9$, and the light conversion efficiency by $\varepsilon=\varepsilon_{0}\left(C_{i}-\Gamma\right) /\left(C_{i}+2 \Gamma\right)$, where $\varepsilon_{0}$ is the maximum quantum use efficiency (Table 2). Finally,

$$
\begin{aligned}
g_{s}= & g_{c}+1.6\left(A_{n}-A_{\min } \frac{D_{s}}{D_{\text {max }}^{*}}\left(\frac{A_{n}+R_{d}}{A_{m}+R_{d}}\right)\right. \\
& \left.+R_{d}\left(1-\frac{A_{n}+R_{d}}{A_{m}+R_{d}}\right)\right) /\left(C_{s}-C_{i}\right),
\end{aligned}
$$

where $A_{\min }$ represents the residual photosynthesis rate (at full light intensity) associated with cuticular transfers when the stomata are closed because of a high saturation deficit:

$A_{\min }=g_{m}^{*} g_{c}\left(C_{s}-\Gamma\right) /\left(g_{m}^{*}+g_{c}\right)$.

\section{Appendix B \\ Forest response to soil moisture stress}

The results presented in Calvet et al. (2004) for maritime pine and sessile oak were used to build a general schematic parameterisation of the effects of the soil moisture stress in the $\mathrm{A}-\mathrm{g}_{s}$ model, for trees. The stress function is expressed as a relative extractable soil water content, defined as

$\theta=\frac{w-w_{w i l t}}{w_{f c}-w_{w i l t}}$,

where $w$ is the soil volumetric moisture in the root-zone, and $w_{f c}$ and $w_{w i l t}$ (Table 1) are the root-zone moisture content at field capacity and wilting point, respectively.

The parameterisation was the following:

- In the drought-avoiding strategy, for values of $\theta$ higher than the critical extractable soil moisture, $\theta_{C}$ (that is for moderate soil moisture stress), $f_{0}$ (Appendix A) deviated from its unstressed value $f_{0} *$ through

$f_{0}=f_{0}^{N}+\left(f_{0}^{*}-f_{0}^{N}\right)\left(\theta-\theta_{C}\right) /\left(1-\theta_{C}\right)$,

where $f_{0}^{N}$ is the stressed value of $f_{0}$ corresponding to the constant unstressed mesophyll conductance, $g_{m} *$. 
- In the drought-tolerant strategy, $g_{m}$ deviated from its unstressed value $g_{m} *$ through

$g_{m}=g_{m}^{N}+\left(g_{m}^{*}-g_{m}^{N}\right)\left(\theta-\theta_{C}\right) /\left(1-\theta_{C}\right)$,

where $g_{m}^{N}$ is the stressed value of $g_{m}$ corresponding to the constant unstressed coupling factor $f_{0}$ *

- For values of $\theta$ below $\theta_{C}$, (i.e. for more pronounced water stress)

$g_{m}=g_{m}^{N} \theta / \theta_{C}$

in the drought-tolerant strategy, while

$g_{m}=g_{m}^{*} \theta / \theta_{C}$

in the drought-avoiding strategy, and $f_{0}$ was derived from $g_{m}$ by inverting the stressed regression line relating the values of $g_{m}$ to $f_{0}$ in stressed conditions:

$\ln \left(g_{m}\right)=2.8-7.0 f_{0} \quad\left(n=29, R^{2}=76 \%\right)$.

This regression equation was obtained by Calvet et al. (2004) by pooling the $g_{m}$ and $f_{0}$ estimates of both maritime pine and sessile oak for low values of extractable soil moisture $(\theta<0.13)$.

- For the lowest values of $\theta$ the value of $f_{0}$ was forced to be lower than 0.99 in order to avoid non-physical values of $g_{s}$ (in Eq. (A5) $C_{s}$ must be higher than $C_{i}$ ). In stressed conditions, the values of $g_{m} *$ and $f_{0} *$ in Eqs. (A1), (A3), and (A6) were replaced by $g_{m}$ and $f_{0}$. The value of $D_{\max } *$ remained unchanged.

\section{Appendix C \\ Estimating canopy conductance from flux measurements}

All the micrometeorological measurements required to perform a $g_{s}-D_{s}$ analysis at the canopy scale (heat and water vapour fluxes, surface temperature, air temperature and humidity, LAI) were available for the Le-Bray experimental stand. Following Calvet (2000), it was possible to estimate the equivalent stomatal conductance at the canopy scale $\left(g_{s}^{\prime}\right)$ using estimates of the effective saturation deficit of the canopy $\left(D_{s}^{\prime}\right)$, and measurements of LAI and evaporative fluxes:

$g_{s}^{\prime}=\frac{E}{\rho_{a} L D_{s}^{\prime}}$,

where $E, L$ and $\rho_{a}$ represent transpiration, LAI, and air density, respectively. The value of the canopy transpiration $E$ was not measured directly but rainless days were considered and it was assumed that the evapotranspiration measurements could be used to estimate the forest transpiration. Indeed, for rainless days, there is no evaporation from the water intercepted by the leaves, and direct soil evaporation is generally low for forest canopies because the litter layer reduces the water vapour exchanges between the soil and the atmosphere.

The effective saturation deficit of the canopy was obtained from meteorological variables (air temperature $T_{a}$, and specific humidity $q_{a}$ ) measured on the flux tower, together with the infrared temperature $T_{s}$, evaporation $E$ and heat fluxes $H$ :

$D_{s}^{\prime}=\left\{q_{s a t}\left(T_{s}\right)-q_{a}\right\}-c_{p}\left\{\frac{E}{H}\right\}\left\{T_{s}-T_{a}\right\}$,

where $c_{p}$, and $q_{s a t}$ are the specific heat of air, and the specific air humidity at saturation, respectively. In this equation, vertical temperature gradients in the canopy are assumed to be small.

The values of $D_{s}^{\prime}$ and $g_{s}^{\prime}$ were calculated for all soil moisture situations, in conditions which were favourable to the expression of a significant physiological response of the canopy to soil and atmospheric water stress: no rain, values of incoming solar radiation $\left(R_{g}\right)$, latent flux $(E)$ and sensible flux $(H)$ higher than 400,40 and $10 \mathrm{~W} \mathrm{~m}^{-2}$, respectively.

\section{Appendix D \\ Accounting for undergrowth vegetation in ISBA-A-g $g_{s}$}

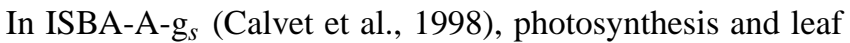
conductance are calculated at several levels in the canopy, and the obtained values are combined to obtain the canopy integrated net assimilation and conductance $\left(A_{n I}\right.$ and $g_{s I}$, respectively). The integration is performed through a 3-point Gauss quadrature method, following Jacobs (1995):

$A_{n I}=L \times \sum_{i=1}^{3} W_{i} A_{n}\left(z_{i}\right)$

$g_{s I}=L \times \sum_{i=1}^{3} W_{i} g_{s}\left(z_{i}\right)$,

where $z_{i}$ and $W_{i}$ are the Gauss levels and weights, respectively, and $L$ represents total LAI.

In the case of Le-Bray, a simple way of including the distinct behaviour of the purple moor-grass undergrowth is to run the $\mathrm{A}-\mathrm{g}_{s}$ model with the purple moor-grass parameters for the near-floor Gauss level, corresponding to the lowest incident radiation. The proportion of LAI corresponding to the purple moor-grass undergrowth is $1 / 3$, and measurements indicate that about $20 \%$ of the incident solar radiation reached the undergrowth. Since the lowest-level Gauss weight is about $1 / 3\left(W_{3}=0.28\right)$, and since the employed radiative transfer equations predict a residual solar radiation at the lowest Gauss level of about 20\%, Eqs. (D1-2) should be sufficient to account for the effect of the undergrowth vegetation on the fluxes. Note that the total LAI value is the same whether the properties of the undergrowth are accounted for or not. 
Acknowledgements. Topical Editor O. Boucher thanks B. van der Hurk and another referee for their help in evaluating this paper.

\section{References}

Anthoni, P. M., Unsworth, M. H., Law, B. E., Irvine, J., Baldocchi, D. D., Van Tuyl, S., and Moore, D.: Seasonal differences in carbon and water vapor exchange in young and old-growth ponderosa pine ecosystems, Agric. For. Meteorol., 111(3), 203-222, 2002.

Baldocchi, D. D. and Wilson, K. B.: Modeling $\mathrm{CO}_{2}$ and water vapor exchange of a temperate broadleaved forest across hourly to decadal time scales, Ecol. Modelling, 142(1-2), 155-184, 2001.

Berbigier, P., Bonnefond, J. M., and Mellmann, P.: $\mathrm{CO}_{2}$ and water vapour fluxes for 2 years above Euroflux forest site, Agric. For. Meteorol., 108, 183-197, 2001.

Calvet, J.-C., Noilhan, J., Roujean, J.-L., Bessemoulin, P., Cabelguenne, M., Olioso, A., and Wigneron, J.-P.: An interactive vegetation SVAT model tested against data from six contrasting sites, Agric. For. Meteorol., 92, 73-95, 1998.

Calvet, J.-C.: Investigating soil and atmospheric plant water stress using physiological and micrometeorological data, Agric. For. Meteorol., 103, 229-247, 2000.

Calvet, J.-C., Rivalland, V., Picon-Cochard, C., and Guehl, J.-M.: Modelling forest transpiration and $\mathrm{CO}_{2}$ fluxes - Response to soil moisture stress, Agric. For. Meteorol., 124(3-4), 143-156, doi: 10.1016/j.agrformet.2004.01.007, 2004.

Collatz, G. J., Ball, J. T., Grivet, C., and Berry, J.A.: Physiological and environmental regulation of stomatal conductance, photosynthesis and transpiration: a model that includes a laminar boundary layer, Agric. For. Meteorol., 54, 107-136, 1991.

Déqué, M., Marquet, P., and Jones, R. G.: Simulation of climate change over Europe using a global variable resolution general circulation model. Clim. Dyn., 14(3), 173-189, 1998.

Delire C., Calvet, J.-C., and Noilhan, J.: Physical properties of Amazonian soils: A modeling study using the Anglo-Brazilian Amazonian Climate Observation Study data. J. Geophys. Res., 102(D25), 30 119-30 133, 1997.

Delpech, F.: Etude des vitesses de circulation de l'eau en sol sableux (horizons saturés et non saturés), Technical report, CEMAGREF-Bordeaux, Cestas, 57 pp., 1996.

Hassika P., Berbigier, P., and Bonnefond, J. M.: Measurement and modelling of the photosynthetically active radiation transmitted in a canopy of maritime pine, Ann. Sc. For., 54, 715-730, 1997.

Jacobs, C. M. J.: Direct impact of atmospheric $\mathrm{CO}_{2}$ enrichment on regional transpiration, Ph.D. Thesis, Agricultural University, Wageningen, 1995.

Jacobs, C. M. J., van den Hurk, B. J. J. M., and de Bruin, H. A. R.: Stomatal behaviour and photosynthetic rate of unstressed grapevines in semi-arid conditions, Agric. For. Meteorol., 80, 111-134, 1996.

Kerstiens, G.: Cuticular water permeability and its physiological significance. J. Exp. Bot., 47(305), 1813-1832, 1996.

Lafore, J.-P., Stein, J., Asencio, N., Bougeault, P., Ducrocq, V., Duron, J., Fischer, C., Héreil, P., Mascart, P., Masson, V., Pinty, J.-P., Redelsperger, J.-L., Richard, E., and Vilà-Guerau de Arellano, J.: The Meso-NH Atmospheric Simulation System, Part I: adiabatic formulation and control simulations. Scientific objectives and experimental design, Ann. Geophys., 16, 90-109, 1998 ,

\section{SRef-ID: 1432-0576/ag/1998-16-90.}

Lagouarde, J. P., Brunet, Y., André, R. G. B., Montembault, D., and Courrier, G.: Utilisation de la température de surface sur la forêt de pin maritime des Landes (Sud-Ouest de la France): résultats préliminaires, Actes du 6ème Symposium International, ISPRS-CNES-INRA-ESA-CNRS-NASA. Mesures physiques et signatures en télédétection, Val d'Isère, 801-808, 1994.

Lamaud, E., Ogée, J., Brunet, Y., and Berbigier, P.: Validation of flux measurements above the undergrowth of a pine forest, Agric. For. Meteorol., 106, 187-203, 2001.

Loustau, D., Granier, A., and El Hadj Moussa, F.: Evolution saisonnière de sève dans un peuplement de pins maritimes, Ann. Sci. For., 21, 599-618, 1990.

Loustau, D. and Cochard H.: Utilisation d'une chambre de transpiration portable pour l'estimation de l'évaporation d'un sous-bois de pin maritime à Molinie (Molinia coerulea $(\mathrm{L})$ Moench), Ann. Sci. For., 48, 29-45, 1991.

Noilhan, J. and Planton S.: A simple parameterisation of land surface processes for meteorological models, Mon. Wea. Rev., 117, 536-549, 1989.

Noilhan, J. and Lacarrère, P.: GCM gridscale evaporation from mesoscale modeling, J. Climate, 8, 206-223, 1995.

Noilhan, J., and Mahfouf, J.F.: The ISBA land surface parametrisation scheme. Global Planet. Change, 13, 145-159, 1996.

Ogée, J., Lamaud, E., Brunet, Y., Berbigier, P., and Bonnefond, J. M.: A long-term study of soil heat flux under a forest canopy, Agric. For. Meteorol., 106, 173-186, 2001.

Ogée, J. and Brunet, Y.: A forest floor model for heat and moisture including a litter layer, J. Hydrol., 255(1-4), 212-233, 2002.

Ogée, J., Brunet, Y., Loustau, D., Berbigier, P., and Delzon, S.: MuSICA, a $\mathrm{CO}_{2}$, water and energy multi-layer, multi-leaf pine forest model: evaluation from hourly to yearly time scales and sensitivity analysis, Global Change Biol., 9, 697-717, 2003.

Picon, C., Guehl, J. M., and Ferhi, A.: Leaf gas exchange and carbon isotope composition responses to drought in a droughtavoiding (Pinus pinaster) and a drought-tolerant (Quercus petraea) species under present and elevated atmospheric CO2 concentrations, Plant, Cell Environ., 19, 182-190, 1996.

Porté, A.: Modélisation des effets du bilan hydrique sur la production primaire et la croissance d'un couvert de Pin maritime (Pinus pinaster Aït) en Lande Humide, Ph.D. Thesis, Université Paris XI, 197 pp., 1999.

Tenhunen, J. D., Valentini, R., Köstner, B., Zimmermann, R., and Granier, A.: Variation in forest gas exchange at landscape to continental scales, Ann. Sci. For., 55, 1-11, 1998.

Valentini, R., Baldocchi, D., and Olson, R.: FLUXNET: A challenge that is becoming reality, Global Change News Letter, 37, 15-17, 1999.

Verhoef A., de Bruin, H. A., and van Der Hurk, B. J. J. M.: Some practical notes on the $\mathrm{kB}^{-1}$ for sparse vegetation, J. Appl. Meteorol., 36, 560-572, 1997.

Wilson, K. B. and Baldocchi, D. D.: Seasonal and interannual variability of energy fluxes over a broadleaved temperate deciduous forest in North America, Agric. For. Meteorol., 100(1), 1-18, 2000.

Wilson, K. B., Hanson, P. J., Mulholland, P. J., Baldocchi, D. D., and Wullschleger, S. D.: A comparison of methods for determining forest evapotranspiration and its components: sap-flow, soil water budget, eddy covariance and catchment water balance, Agric. For. Meteorol., 106(2), 153-168, 2001. 